\title{
BIBLIOTECA UNIVERSITÁRIA COMO ESPAÇO DE DISCUSSÃO EM GÊNERO E SEXUALIDADE: PÚBLICO TRANS NA BIBLIOTECA CENTRAL DA UNIVERSIDADE FEDERAL DE GOIÁS.
}

\author{
Luiz Felipe Pereira Nunes \\ luiz.nunes@ifac.edu.br \\ Bibliotecário do Instituto Federal do Acre \\ Orientadora: Elisângela Gomes \\ Professora da Faculdade de Informação e Comunicação - UFG
}

\section{Resumo}

Compreender o papel social da biblioteca universitária como proponente de discussões de gênero e sexualidades com recorte de público trans. Este trabalho se mostra necessário a partir do fato de que a biblioteca universitária tem como dever ser um espaço para a propagação de cultura e do desenvolvimento do pensamento crítico. Sendo assim ao partir da ausência de ações culturais para o público trans na biblioteca, este trabalho propôs através de pesquisa ação a realização de uma exposição fotográfica e roda de conversa para debater a importância da biblioteca universitária como agente de formação e transformação cidadã. Este estudo teve abordagem qualitativa. Foram coletadas informações a partir de questionários realizadas na proposta de ação cultural com estudantes da Universidade Federal de Goiás, cisgênero e Transgênero. Este trabalho demonstra que a biblioteca universitária é um espaço para se trabalhar gênero e sexualidades.

Palavras-chave: Biblioteconomia. Gênero e sexualidades. Biblioteca Universitária. 